\title{
Notas. Alvi Geminelli: un economista herético
}

\author{
Alvi Geminelli: An heretical economist
}

\author{
Giuseppe De Corso \\ Director Doctorado en Modelado en Política y Gestión Pública, \\ Universidad de Bogotá Jorge Tadeo Lozano \\ http://orcid.org/0000-0002-4677-5130 \\ giuseppeb.decorsos@utadeo.edu.co
}

Fecha de recepción: 30 de enero de 2017

Fecha de aprobación: 01 de marzo de 2017

Sugerencia de citación: De Corso, G. (2017). Alvi Geminelli: Un economista herético. tiempo\&economía, 4(1), 129-130, doi: http://dx.doi.org/10.21789/24222704.1190

Sin lugar a dudas, uno de mis autores favoritos por lo iconoclasta de sus posiciones que rompen con los esquemas - muchas veces soporíferos y repetitivos - de la economía actual es Geminello Alvi.

Alvi es uno de los economistas italianos y europeos más interesantes y, me atrevería a decir, con una cultura densa no muy característica de la profesión hoy en día: un autor con una visión típica del hombre renacentista. Si uno quisiera encasillarlo en un enfoque, tendría que escoger catalogarlo como un outsider, un economista herético, es decir ni ortodoxo ni heterodoxo, siguiendo las denominaciones usuales en el mundo académico. Alvi fungió por años como asistente del gobernador de Banco Central de Italia, Paolo Baffi, en el Banco de Pagos Internacionales de Basilea (fundado en 1930). Asimismo, ha trabajado como editorialista del Corriere della Sera y La Repubblica, editor de la revista económica Surplus, miembro del consejo editorial de la revista Limes (geopolítica), del consejo científico de la Fundación Eni (Ente Nazionale Idrocarburi) e integrante del Consejo de Expertos del Ministerio de Economía y Finanzas. Ha publicado unos trece libros y diversos papers. Entre los libros se pueden resaltar: Una repubblica fondata sulle rendite. Come sono cambiati il lavoro e la ricchezza degli italiani (Milano, Mondadori, 2006); trabajo realizado para el Ministerio de Economía en donde propuso una forma diversa de medir la riqueza 'real' de la sociedad italiana, alejada de los convencionalismos metodológicos de 
las cuentas nacionales, que manejan las multilaterales, con todas las imprecisiones y defectos que conocemos. Este trabajo Alvi lo sustenta en una reinterpretación teórica-metodológica de los clásicos, analizando el flujo y el inventario de la riqueza de las familias italianas. Sus resultados son sorprendentes cuando se contrastan con las mediciones tradicionales empleadas por el Instituto Nacional de Estadísticas italianas (ISTAT). En II Capitalismo. Verso l'ideale cinese (Venezia, Marsilio, 2011) propone una disquisición novedosa en la cual desanuda la estructura del 'capitalismo' chino como una renovada confluencia del comunismo asiático y el confucionismo. En Le seduzioni economiche di Faust (Milano, Adelphi, 1989) efectúa un excursus en el pensamiento económico del siglo XX, siendo muy crítico — pudiera decirse ácido- tanto del marxismo - simplemente impracticable - como de las posturas neoclásicas, a las cuales considera secuela del dominio anglosajón después de la victoria en la Segunda Guerra Mundial.

Alvi critica la ciencia económica moderna como un intento - casi siempre fallido en el largo plazo- de reducir la misma a un cálculo mecánico. Las instituciones económicas son modos de pensamiento, la variación de estos modos individualiza los contextos económicos y explica su evolución e implica instituciones predispuestas a la función distributiva alejadas del mercado. Además, habla de la necesidad de la economía de la donación (dono) y la desacumulación (decumulo) como formas de equilibrar la economía mundial y superar desequilibrios o crisis y pone como ejemplos el Plan Marshal y la reforma monetaria Alemana de 1948. En fin, muchas son las ideas que adelanta Alvi que nada tienen en común con el pensamiento económico hegemónico. En este sentido, Alvi recurre usualmente a un método, o estilo, que pudiera hoy considerarse - o criticarse- como arcaico y es el de la escuela historicista alemana de economía, que en nuestra opinión no ha recibido los suficientes créditos como inspiradora de la escuela económica institucional norteamericana. Sus textos abarcan una gran cantidad de argumentos psicológicos, sociológicos, literarios, antropológicos, jurisprudenciales, geopolíticos y, obviamente, económicos. Resuena la lógica de Alvi de la narrativa del socioeconomista Werner Sombart — quien fue desterrado y olvidado por sus nexos con el nacionalsocialismo alemán- en libros tales como El Burgués, Capitalismo y lujo, Capitalismo y guerra y Der moderne Kapitalismus, en seis volúmenes.

Alvi sigue de cerca el paradigma evolucionista de Sombart, pero asimismo, la geopolítica y el marco jurídico europeo e internacional de otro alemán: Carl Schmitt (Nomos de la Tierra y, en menor medida, de Tierra y mar). Es decir, la disputa por el poder mundial entre las talasocracias (imperios del mar) y telurocracias (imperios continentales) y cómo estas luchas determinan los caminos de la teoría económica, la libertad de comercio tan idolatrada por las potencias marítimas y las tendencias autárquicas de los imperios continentales.

En conclusión, la lectura de la obra de Geminello Alvi es una bocanada de aire fresco en un contexto donde predominan ad infinitum las mismas propuestas de política económica que son como aquellos vinos viles, donde cambia la botella pero no el contenido. Alvi, en cierta forma, representa uno de los últimos economistas mitteleuropeo a la vieja usanza (con las diferencias del caso) como Gustav von Schmoller, Bruno Hildebrand, Georg Friedrich Knapp y Werner Sombart, entre otros. 